\title{
Bioremediation of Mercury by Vibrio fluvialis Screened from Industrial Effluents
}

\author{
Kailasam Saranya, ${ }^{1}$ Arumugam Sundaramanickam, ${ }^{1}$ Sudhanshu Shekhar, ${ }^{1}$ \\ Sankaran Swaminathan, ${ }^{2}$ and Thangavel Balasubramanian ${ }^{1}$ \\ ${ }^{1}$ CAS in Marine Biology, Faculty of Marine Sciences, Annamalai University, Parangipettai 608 502, India \\ ${ }^{2}$ AVC College of Arts and Science, Mannampandal, Mayiladuthurai 609 305, India
}

Correspondence should be addressed to Arumugam Sundaramanickam; fish_lar@yahoo.com

Received 11 February 2017; Revised 19 March 2017; Accepted 19 April 2017; Published 25 May 2017

Academic Editor: Raluca M. Hlihor

\begin{abstract}
Copyright (C) 2017 Kailasam Saranya et al. This is an open access article distributed under the Creative Commons Attribution License, which permits unrestricted use, distribution, and reproduction in any medium, provided the original work is properly cited.

Thirty-one mercury-resistant bacterial strains were isolated from the effluent discharge sites of the SIPCOT industrial area. Among them, only one strain (CASKS5) was selected for further investigation due to its high minimum inhibitory concentration of mercury and low antibiotic susceptibility. In accordance with $16 \mathrm{~S}$ ribosomal RNA gene sequences, the strain CASKS5 was identified as Vibrio fluvialis. The mercury-removal capacity of $V$. fluvialis was analyzed at four different concentrations $(100,150,200$, and $250 \mu \mathrm{g} / \mathrm{ml})$. Efficient bioremediation was observed at a level of $250 \mu \mathrm{g} / \mathrm{ml}$ with the removal of $60 \%$ of mercury ions. The interesting outcome of this study was that the strain $V$. fluvialis had a high bioremediation efficiency but had a low antibiotic resistance. Hence, $V$. fluvialis could be successfully used as a strain for the ecofriendly removal of mercury.
\end{abstract}

\section{Introduction}

Mercury is one of the most hazardous heavy metals, which is considered as a significant contaminant of the environment. Mercury contamination and its threat to the environment and living organisms is a worldwide problem [1]. It is released into the environment in two ways: natural events and human activities. When compared to the natural processes, human activities have been discharging excessive amounts of mercury into the environment [2]. A primary source of mercury pollution is chloralkali plants, paper pulps, amalgamation industries, fungicides, and paints [3]. The potential of mercury toxicity is only based on its combination with, for example, sulfide, oxide, hydroxide, chloride, and methyl groups. After the incident of Minamata Bay in Japan, mercury poisoning to human health has become evident [4]. A small amount of mercury can have dangerous effects for months in human beings, animals, and plants and even affect the growth of bacteria in microorganisms although some bacteria are capable of surviving and growing in mercurycontaminated sites [5]. Most of the mercury-refinement processes follow common physical and chemical methods, which are highly expensive and have some limitations, whereas biological methods are cost-effective, viable, and friendly to the environment [6]. The use of microorganisms for the removal of metals from contaminated effluents and mining and industrial wastes is considered to be effective because of its efficiency and ecofriendly nature [7]. Recently, the utilization of bacterial biomass under either live or dead conditions for bioremediation has emerged as an efficient, ecofriendly, and cost-effective alternative for the elimination of low concentrations of heavy metals.

The heavy metal and antibiotic-resistant bacteria were found in normal and polluted environments which is a worldwide problem [8]. An array of heavy metals and antibiotics, at concentrations found in different polluted environments, have the potential to coselect both metal-antibiotic-resistant strains and their plasmids [9]. The bacterial agent associated with coselective mechanism of metal-antibiotics is significant at higher threats. Hence, in the present investigation the strain was selected based on the mercury resistance and 
TABLE 1: Similarity of minimum inhibitory mercury concentration value against that observed in the present strain Vibrio fluvialis to those reported elsewhere.

\begin{tabular}{lccc}
\hline Strain & MIC $(\mu \mathrm{g} / \mathrm{ml})$ & Location & Reference \\
\hline Vibrio fluvialis & 1 & Tagus Estuary (Portugal) & Figueiredo et al., 2016 \\
Vibrio natriegens & 20 & Coastal sediments, Bushehr, Iran & Jafari and Cheraghi, 2014 \\
Vibrio sp. & $12-16$ & Chesapeake Bay & Walker and Colwell, 1974 \\
Vibrio sp. & 2.71 & Mai Po Nature Reserve, Hong Kong & Zhang et al., 2006 \\
Vibrio parahaemolyticus & 45 & Coastal sediments, Bushehr, Iran & Jafari and Cheraghi, 2014 \\
Vibrio fluvialis & 100 & Parangipettai coast (India) & Present study \\
\hline
\end{tabular}

antibiotic susceptible characteristics. Subsequently, its bioremediation capability was investigated.

\section{Methods and Materials}

2.1. Sample Collection. Sediment samples were collected from the common effluent discharge point of the State Industries Promotion Corporation of Tamil Nadu Limited (SIPCOT) industrial area located in the banks of the Uppanar estuary, Tamil Nadu, southeast coast of India. The geographic coordinates of the station are $11^{\circ} 41^{\prime} 45.00^{\prime \prime} \mathrm{N}$ latitude and $79^{\circ} 46^{\prime} 05.00^{\prime \prime} \mathrm{E}$ longitude. Surface sediments were collected aseptically in triplicate, kept in an insulated box at $4^{\circ} \mathrm{C}$, and immediately transferred to the laboratory.

2.2. Enrichment and Primary Screening. Sediment samples were added to a $250 \mathrm{ml}$ Erlenmeyer flask containing $100 \mathrm{ml}$ of Zobell Marine Broth (ZMB) at pH 7.1 \pm 0.1 , incubated for $24 \mathrm{~h}$ and centrifuged at $160 \mathrm{rpm}$ at $35^{\circ} \mathrm{C}$ in a conventional rotary shaker incubator. The bacterial inocula were transferred to a $100 \mathrm{ml} \mathrm{ZMB}$ with a supplement of $\mathrm{HgCl}_{2}$ and kept in an orbital shaker at $200 \mathrm{rpm}$ for 5 days.

2.3. Antibiotic Sensitivity Test. Antibiotic sensitivity test was performed using the disc diffusion method on $\mathrm{MH}$ agar with antibiotic disks, by following the methods of CLSI (2013) [10]. Multiple antibiotic profiles of $V$. fluvialis were checked at the following antibiotic concentrations: amoxicillin (10 mcg/disc), bacitracin (10 mcg/disc), erythromycin (15 mcg/disc), amoxicillin (10 mcg/disc), bacitracin $(10 \mathrm{mcg} /$ disc), erythromycin $(15 \mathrm{mcg} / \mathrm{disc})$, oxytetracycline $(30 \mathrm{mcg} /$ disc), novobiocin (30 mcg/disc), cephalothin (30 mcg/disc), vancomycin (30 mcg/disc), and amikacin (10 mcg/disc). Bacterial cultures swabbed on nutrient agar plates and the abovementioned antibiotics discs were placed in the plates and incubated at $37^{\circ} \mathrm{C}$ for $24 \mathrm{hrs}$.

2.4. Growth Assessment of CASKS5 with Mercury. The selected $V$. fluvialis overnight culture was inoculated into the nutrient broth, which was supplemented at different concentrations of $\mathrm{HgCl}_{2}$ such as $100 \mu \mathrm{g} / \mathrm{ml}, 150 \mu \mathrm{g} / \mathrm{ml}, 200 \mu \mathrm{g} / \mathrm{ml}$, and $250 \mu \mathrm{g} / \mathrm{ml}$ in triplicate and kept in a shaking incubator at $37^{\circ} \mathrm{C}$ for $48 \mathrm{hrs}$. Growth curves of $\mathrm{V}$. fluvialis were observed at periodic time intervals, that is, $2,4,8,16,24$, and $48 \mathrm{hrs}$ using a spectrophotometer (SHIMADZU UV 1800) at $600 \mathrm{~nm}$ OD.

2.5. Bioremediation Capacity of CASKS5. After the completion of the incubation period, the cultures were centrifuged for $20 \mathrm{mins}$ at $10000 \mathrm{rpm}$, pellets removed, and supernatants collected and digested with nitric and sulfuric acids. The residual mercury in the medium was analyzed by a cold vapor mercury analyzer (Model MA 5840).

\section{Results and Discussion}

Mercury-resistant bacterial strains were initially screened using the Luria Bertani (LB) medium in the presence of $2.0 \mu \mathrm{g} / \mathrm{ml} \mathrm{HgCl}_{2}$ from sediment samples collected at effluent discharge sites.

3.1. Isolation, Screening, and Selection of Mercury-Resistant Bacteria. The high mercury-resistant strains were isolated from sediments of industrial discharge sites using several screening techniques. Prolonged exposure to mercury contamination can generate resistance mechanisms in bacteria [11]. During preliminary findings, 31 bacterial isolates exhibited high resistance to mercury. Secondary screening was performed to estimate MIC. The MIC results observed for all the 31 isolates confirmed that the strain CASKS5 had the highest mercury tolerance $(100 \mu \mathrm{g} / \mathrm{ml}$ concentration) as shown in Table 1, which is several times greater than that obtained in an earlier study done on the same species by Figueiredo et al. (2016) [12].

3.2. Biochemical Characterization and Molecular Identification of CASKS5. The selected strain CASKS5 was morphologically and biochemically characterized as a gram-negative, curved rod-shaped bacterium and tentatively identified as Vibrio sp. (Table 2). The $16 \mathrm{~S}$ rDNA sequence was carried out for CASKS5 and submitted to GenBank (NCBI, 2013) for searching similar published sequences. The accession number of the strain CASKS5 is KM186606.

BLAST analysis revealed that the partial 16S rDNA of CASKS5 had more than 99\% similarity to that of Vibrio fluvialis strain in NCBI. A phylogenetic tree based on 16S rDNA was constructed using the MEGA 6.0 software to determine the relationship between CASKS5 and V. fluvialis (Figure 1). 


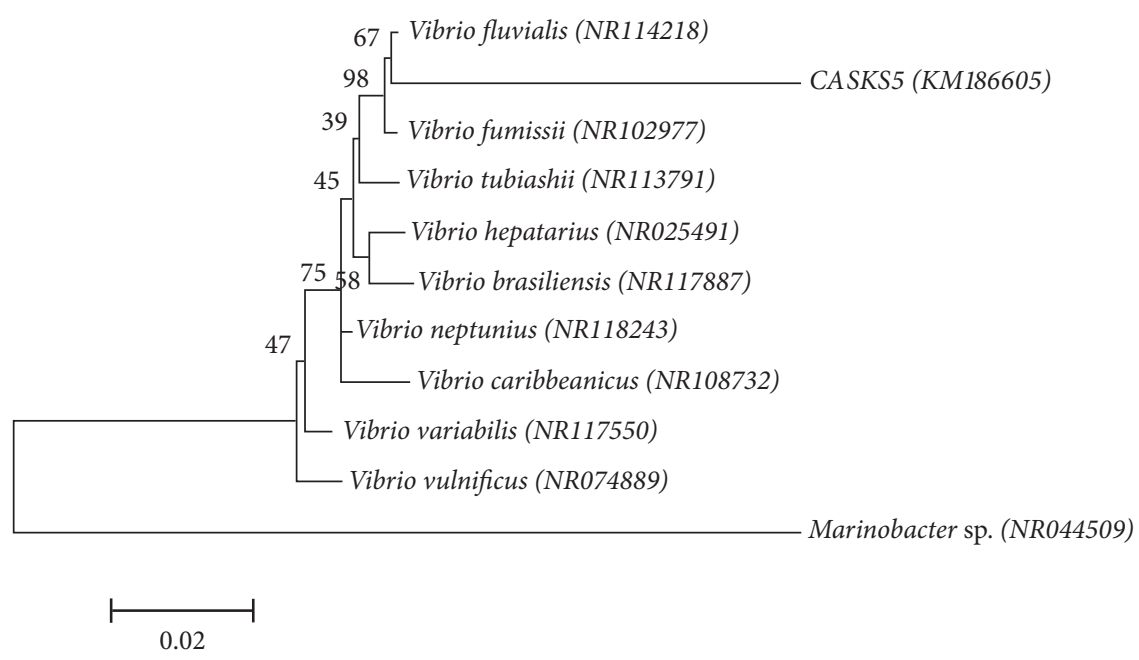

FIGURE 1: Phylogenetic tree constructed from the 16S rRNA gene sequence of Vibrio fluvialis (KM186605) (GenBank accession number KM186605) and closely related organisms using NCBI BLAST. The scale bar represents 0.02 substitutions per nucleotide position.

TABLE 2: Biochemical characteristics of strain mercury resistant bacterial strain CASKS5.

\begin{tabular}{lcc}
\hline Tests & Morphology & Results \\
\hline Gram reaction & & -ve \\
Shape & Biochemical reactions & Rod \\
\hline & & + \\
Citrate utilisation & & + \\
Indole & - \\
Methyl red & + \\
Nitrate reduction & + \\
Oxidase & + \\
Catalase & - \\
Voges Proskauer & Carbohydrate utilisation & + \\
Gelatin & & + \\
\hline & & - \\
Glucose & & + \\
Sucrosinose & & +
\end{tabular}

Based on the above characterization, strain CASKS5 was identified as V.fluvialis.

3.3. Antibiotic Profile of V. fluvialis. Earlier investigations dealt with the heavy metal resistance of bacteria from marine environments having high resistance to most of the antibiotics [13, 14]. Nakahara et al. [15] stated that antibioticand metal-resistance ability is created by the same plasmid of the bacteria. However, in the present investigation, the results of the antibiotic sensitivity test with eight different antibiotics indicate that the strain CASKS5 was found to be susceptible to the majority of antibiotics, for example, amikacin, erythromycin, novobiocin, oxytetracycline, and vancomycin,

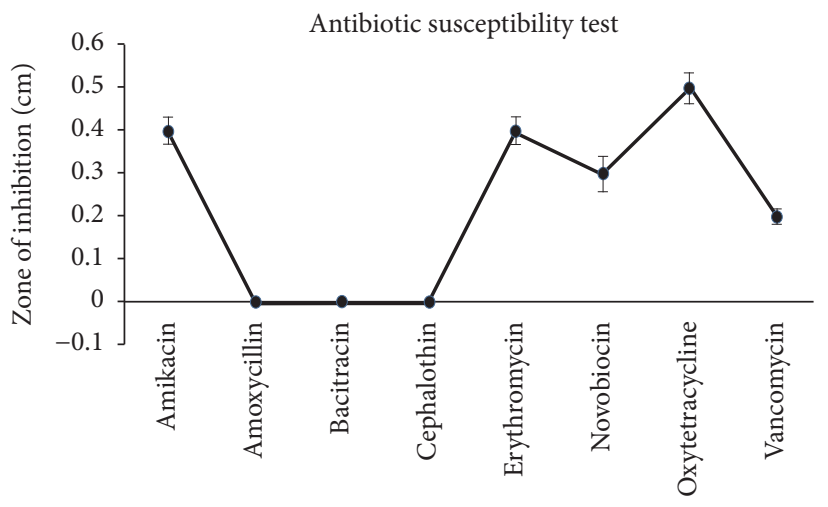

FIGURE 2: Antimicrobial susceptibility test profile for mercuryresistant bacteria isolate Vibrio fluvialis (KM186605).

although it was resistant to only three antibiotics, namely, amoxicillin, bacitracin, and cephalothin (Figure 2). Much controversy exists within the scientific community over whether metal-resistant bacteria from polluted areas can also have antibiotic resistance. In the present investigation, the selected strain proved to have high resistance to mercury, although with little resistance to antibiotics. The results of Figueiredo et al. (2016) [12] specify that, out of 10 bacterial strains isolated from mercury-contaminated regions of the Tagus estuary, only three have multidrug resistance. They also reported that $V$. fluvialis has resistance only to nalidixic acid among the six antibiotics tested. Hence, the presence of these antibiotic- and mercury-resistant genetic elements in the same gene is again highly contentious.

3.4. Effect of Mercury on the Growth of V. fluvialis. Based on the MIC results, $100 \mu \mathrm{g} / \mathrm{ml}$ was taken as an initial metal concentration for growth curve studies. A significant growth rate of $V$. fluvialis was observed after $24 \mathrm{hrs}$ of incubation in 


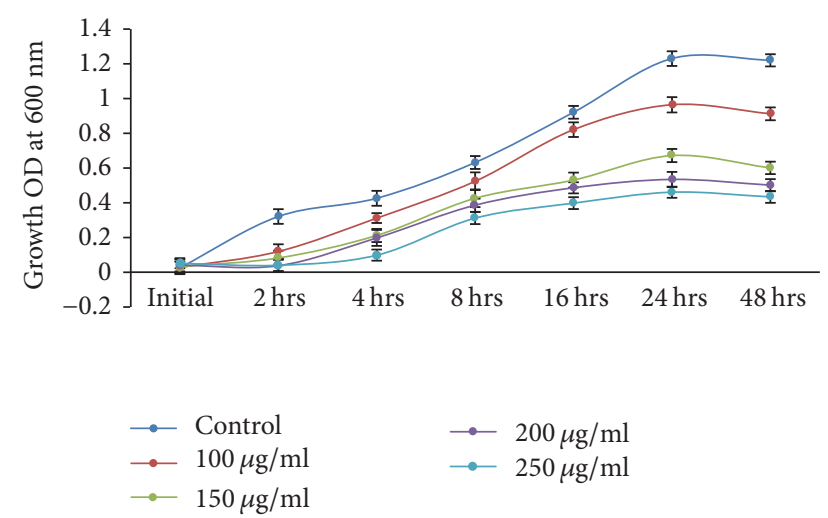

FIGURE 3: Growth kinetics of Vibrio fluvialis (KM186605) in $\mathrm{HgCl}_{2}$ $(100,150,200$, and $250 \mu \mathrm{g} / \mathrm{ml})$ containing medium. Control cultures did not contain any metal ions.

control as well as in culture broth-containing metal, which indicated that gram-negative $V$. fluvialis has developed a potential resistance to mercury. An earlier study by Aram et al. [16] also states that gram-negative bacteria isolated from the Maharloo River, Iran, have higher resistance when compared to gram-positive bacteria. Bioremediation results show that enhanced growth was observed in control as well as solutions with mercury at a lower concentration $(100 \mu \mathrm{g} / \mathrm{ml})$ as compared to higher concentrations $(150 \mu \mathrm{g} / \mathrm{ml}, 200 \mu \mathrm{g} / \mathrm{ml}$, and $250 \mu \mathrm{g} / \mathrm{ml}$ ), which indicates an increase in the concentration of mercury and a decrease in the growth rate of cells (Figure 3). The present observation corroborates an earlier study described by Zeng et al. (2009) [17] from China.

3.5. Mercury-Removal Capacity of V. fluvialis. Bacteria are a valuable tool to treat mercury because they have vital reactive interfaces for the adsorption of nutrients and foreign contaminants on their cell surface; particularly bacterial membranes act as sites of uptake and exudation and provide plenty of enzymatic actions [18]. In the case of metal contaminants, some bacterial cells uptake metals for their requirements, some of them chelate with metals, and some either reduce or oxidize them [19]. Mercury-remediation capacity of $V$. fluvialis was observed by growth carve at different concentrations of mercury chloride. The highest mercury-remediation rate $(60 \%)$ was found at a lower mercury concentration of $100 \mu \mathrm{g} / \mathrm{ml}$ after $42 \mathrm{~h}$ of incubation. At higher concentrations of 150,200 , and $250 \mu \mathrm{g} / \mathrm{ml}$, the mercury-removal percentages were $40,25.33$, and $19 \%$, respectively (Figure 4). Some of the previous works of various researchers on mercury bioremediation by bacterial strains are given in Table 3 . At a mercury concentration of $10 \mu \mathrm{g} / \mathrm{ml}, 89.47 \%$ of the mercury was removed by a species under the same genus, Vibrio parahaemolyticus, over $40 \mathrm{~h}$ of incubation [20]. The results of other bacterial species are as follows: Bacillus sp., 68.1\% [21]; Bacillus thuringiensis, 42.7\% [22]; Pseudomonas aeruginosa, 80\% [23]; Brevibacterium casei, 70\% [23]; Tetrahymena rostrate, 40\% [24];

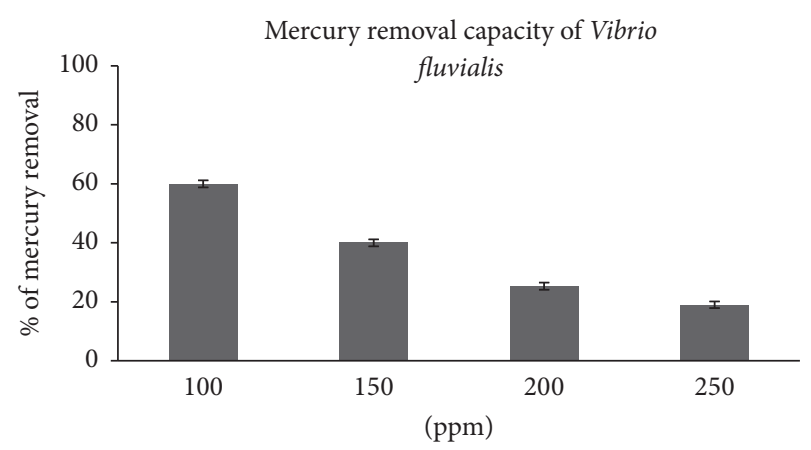

FIGURE 4: Bioremediation efficiency by Vibrio fluvialis (KM186605) with different initial concentration $\mathrm{HgCl} 2(100,150,200$, and 250 $\mu \mathrm{g} / \mathrm{ml})$.

Pseudomonas sp., 65\% [25]; Pseudomonas fluorescens, 34.30\% [26] and 42.7\% [22]; Pseudomonas aeruginosa, 80\% [23]; Brevibacterium casei, 70\% [23]; Tetrahymena rostrate, $40 \%$ [24]; Pseudomonas sp., 65\% [25]; Pseudomonas fluorescens, 34.30\% [26]; Pseudomonas aeruginosa, 25\% [27]; Klebsiella pneumoniae, 15\% [27]; and the Enterobacter cloacae efficiency was below the detectable limit [28]. Some of them observed a better removal of mercury than in the present study. However, the concentration level used in other studies was lower than that in our present investigation which is shown in Table 3.

\section{Conclusion}

The results demonstrate that $V$. fluvialis has strong ability to detoxify mercury from mobile solutions. In addition, mercury and antibiotic resistance were appraised in detail for the selected strain. Generally, metal-resistant strains exhibit a strong antibiotic resistance; nevertheless, the present findings specify that the isolate CASKS5 has resistance to only a few antibiotics. Hence, the strain CASKS5 can be utilized as a good chelating agent for the removal of mercury from contaminated effluents because of its high efficiency. Further studies have to be performed to find out the mechanism behind the removal of mercury by $V$. fluvialis and also to examine the preference for heavy metal uptake by this bacterium in the presence of other heavy metals.

\section{Disclosure}

The paper does not discuss policy issues and the conclusions drawn in the paper are based on interpretation of results by the authors and in no way reflect the viewpoint of the funding agency.

\section{Conflicts of Interest}

The authors declare that there are no conflicts of interest regarding the publication of this paper. 


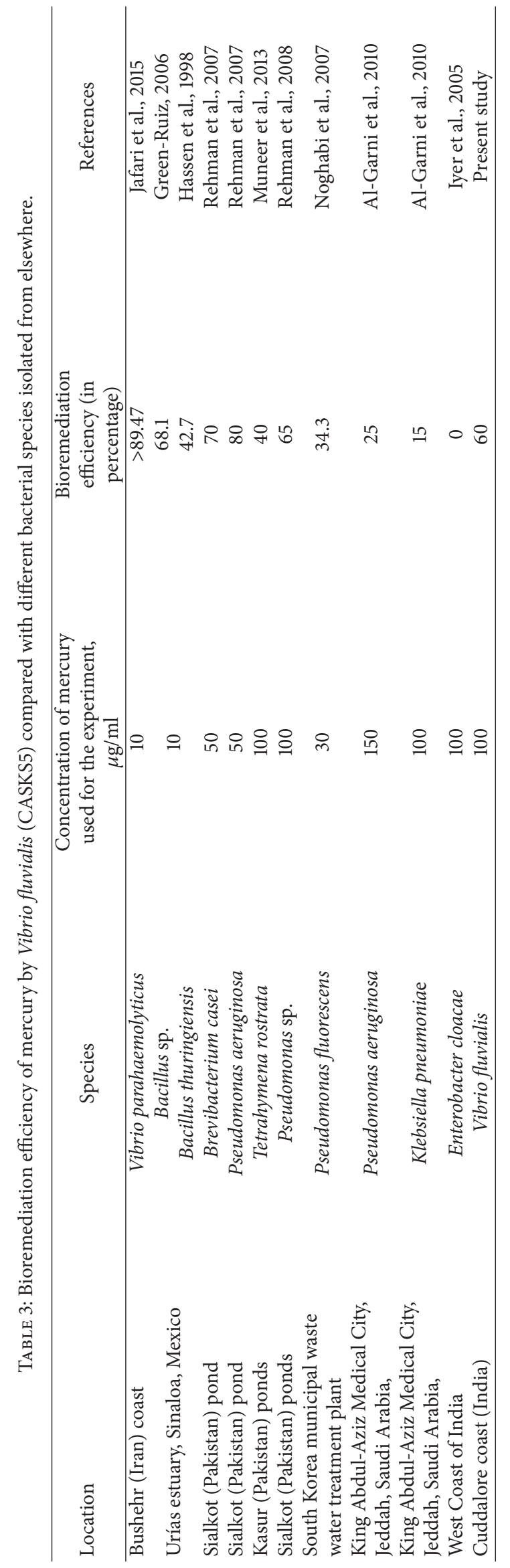




\section{Acknowledgments}

The authors gratefully acknowledge the financial support provided by the ICMAM-PD, Ministry of Earth Sciences, Government of India, Grant no. ICMAM-PD/SWQM/CASMB/ $35 / 2012$ to conduct this research.

\section{References}

[1] S. A. Jafari and S. Cheraghi, "Mercury removal from aqueous solution by dried biomass of indigenous Vibrio parahaemolyticus PG02: kinetic, equilibrium, and thermodynamic studies," International Biodeterioration and Biodegradation, vol. 92, pp. 12-19, 2014.

[2] H. F. Canstein, Y. Li, A. Felske, and I. Wagner-Döbler, "Longterm stability of mercury-reducing microbial biofilm communities analyzed by $16 \mathrm{~S}-23 \mathrm{~S}$ rDNA interspacer region polymorphism," Microbial Ecology, vol. 42, no. 4, pp. 624-634, 2001.

[3] P. Li, X. B. Feng, G. L. Qiu, L. H. Shang, and Z. G. Li, "Mercury pollution in Asia: a review of the contaminated sites," Journal of Hazardous Materials, vol. 168, no. 2-3, pp. 591-601, 2009.

[4] Social Scientific Study Group on Minamata Disease, In the Hope of Avoiding Repetition of Tragedy of Minamata Disease, National Institute for Minamata Disease, Minamata, Japan, 1999.

[5] S. H. Afrasayab, A. Yasmin, and S. H. Hasnain, "Characterization of some indigenous mercury resistant bacteria from polluted environment," Journal of Biological Science, vol. 5, no. 7, pp. 792-797, 2007.

[6] I. Wagner-Döbler, "Pilot plant for bioremediation of mercurycontaining industrial wastewater," Applied Microbiology and Biotechnology, vol. 62, no. 2-3, pp. 124-133, 2003.

[7] A. Sinha, K. K. Pant, and S. K. Khare, "Studies on mercury bioremediation by alginate immobilized mercury tolerant Bacillus cereus cells," International Biodeterioration and Biodegradation, vol. 71, pp. 1-8, 2012.

[8] F. Matyar, "Antibiotic and heavy metal resistance in bacteria isolated from the Eastern Mediterranean Sea coast," Bulletin of Environmental Contamination and Toxicology, vol. 89, no. 3, pp. 551-556, 2012.

[9] E. Gullberg, L. M. Albrecht, C. Karlsson, L. Sandegren, and D. I. Andersson, "Selection of a multidrug resistance plasmid by sublethal levels of antibiotics and heavy metals," mBio, vol. 5, no. 5, Article ID e01918-14, 2014.

[10] Clinical and Laboratory Standards Institute, CLSI M100-S23; Clinical and Laboratory Standards, Clinical and Laboratory Standards Institute, Wayne, 2013.

[11] V. V. Umrania, "Bioremediation of toxic heavy metals using acidothermophilic autotrophes," Bioresource Technology, vol. 97, no. 10, pp. 1237-1242, 2006.

[12] N. L. Figueiredo, J. Canário, N. J. O’Driscoll, A. Duarte, and C. Carvalho, "Aerobic Mercury-resistant bacteria alter Mercury speciation and retention in the Tagus Estuary (Portugal)," Ecotoxicology and Environmental Safety, vol. 124, pp. 60-67, 2016.

[13] S. H. A. Hassan, R. N. N. Abskharon, S. M. F. Gad El-Rab, and A. A. M. Shoreit, "Isolation, characterization of heavy metal resistant strain of Pseudomonas aeruginosa isolated from polluted sites in Assiut city, Egypt," Journal of Basic Microbiology, vol. 48, no. 3, pp. 168-176, 2008.
[14] J. Selvin, S. Shanmugha Priya, G. Seghal Kiran, T. Thangavelu, and N. Sapna Bai, "Sponge-associated marine bacteria as indicators of heavy metal pollution," Microbiological Research, vol. 164, no. 3, pp. 352-363, 2009.

[15] Y. Nakahara, Y. Nakahara, Y. Ito, and T. Ogawa, "Total synthesis of B-chain of human $\alpha 2 \mathrm{HS}$ glycoprotein," Tetrahedron Letters, vol. 38, no. 41, pp. 7211-7214, 1997.

[16] M. Aram, A. Sharifi, F. Kafeelzadeh, M. Naghmachi, and E. Yasari, "Isolating Mercury-resistant bacteria from Lake Maharloo," International Journal of Biology, vol. 4, no. 3, pp. 63-71, 2012.

[17] X. X. Zeng, J. X. Tang, X. D. Liu, and P. Jiang, "Isolation, identification and characterization of cadmium-resistantPseudomonas aeruginosa strain E1," Journal of Central South University of Technology, vol. 16, no. 3, pp. 416-421, 2009.

[18] J. Claessens, T. Behrends, and P. Van Cappellen, "What do acidbase titrations of live bacteria tell us? A preliminary assessment," Aquatic Sciences, vol. 66, no. 1, pp. 19-26, 2004.

[19] F. M. M. Morel and N. M. Price, "The biogeochemical cycles of trace metals in the oceans," Science, vol. 300, no. 5621, pp. 944947, 2003.

[20] S. A. Jafari, S. Cheraghi, M. Mirbakhsh, R. Mirza, and A. Maryamabadi, "Employing response surface methodology for optimization of mercury bioremediation by Vibrio parahaemolyticus PG02 in coastal sediments of Bushehr, Iran," Clean-Soil, Air, Water, vol. 43, no. 1, pp. 118-126, 2015.

[21] C. Green-Ruiz, "Mercury(II) removal from aqueous solutions by nonviable Bacillus sp. from a tropical estuary," Bioresource Technology, vol. 97, no. 15, pp. 1907-1911, 2006.

[22] A. Hassen, N. Saidi, M. Cherif, and A. Boudabous, "Resistance of environmental bacteria to heavy metals," Bioresource Technology, vol. 64, no. 1, pp. 7-15, 1998.

[23] A. Rehman, A. Ali, B. Muneer, and A. R. Shakoori, "Resistance and biosorption of mercury by bacteria isolated from industrial effluents," Pakistan Journal of Zoology, vol. 39, no. 3, pp. 137-146, 2007.

[24] B. Muneer, M. J. Iqbal, F. R. Shakoori, and A. R. Shakoori, "Tolerance and biosorption of mercury by microbial consortia: potential use in bioremediation of wastewater," Pakistan Journal of Zoology, vol. 45, no. 1, pp. 247-254, 2013.

[25] A. Rehman, A. Ali, and A. R. Shakoori, "Biosorption of mercury by bacteria, isolated from industrial effluents: potential use in bioremediation of wastewater," Pakistan Journal of Zoology, vol. 40, no. 2, pp. 115-122, 2008.

[26] K. A. Noghabi, H. S. Zahiri, A. S. Lotfi, J. Raheb, S. Nasri, and S. C. Yoon, "Mercury absorption by Pseudomonas fluorescens BM07 grown at two different temperatures," Polish Journal of Microbiology, vol. 56, no. 2, pp. 111-117, 2007.

[27] S. M. Al-Garni, K. M. Ghanem, and A. S. Ibrahim, "Biosorption of mercury by capsulated and slime layerforming Gram -ve bacilli from an aqueous solution," African Journal of Biotechnology, vol. 9, no. 38, pp. 6413-6421, 2010.

[28] A. Iyer, K. Mody, and B. Jha, "Biosorption of heavy metals by a marine bacterium," Marine Pollution Bulletin, vol. 50, no. 3, pp. 340-343, 2005. 

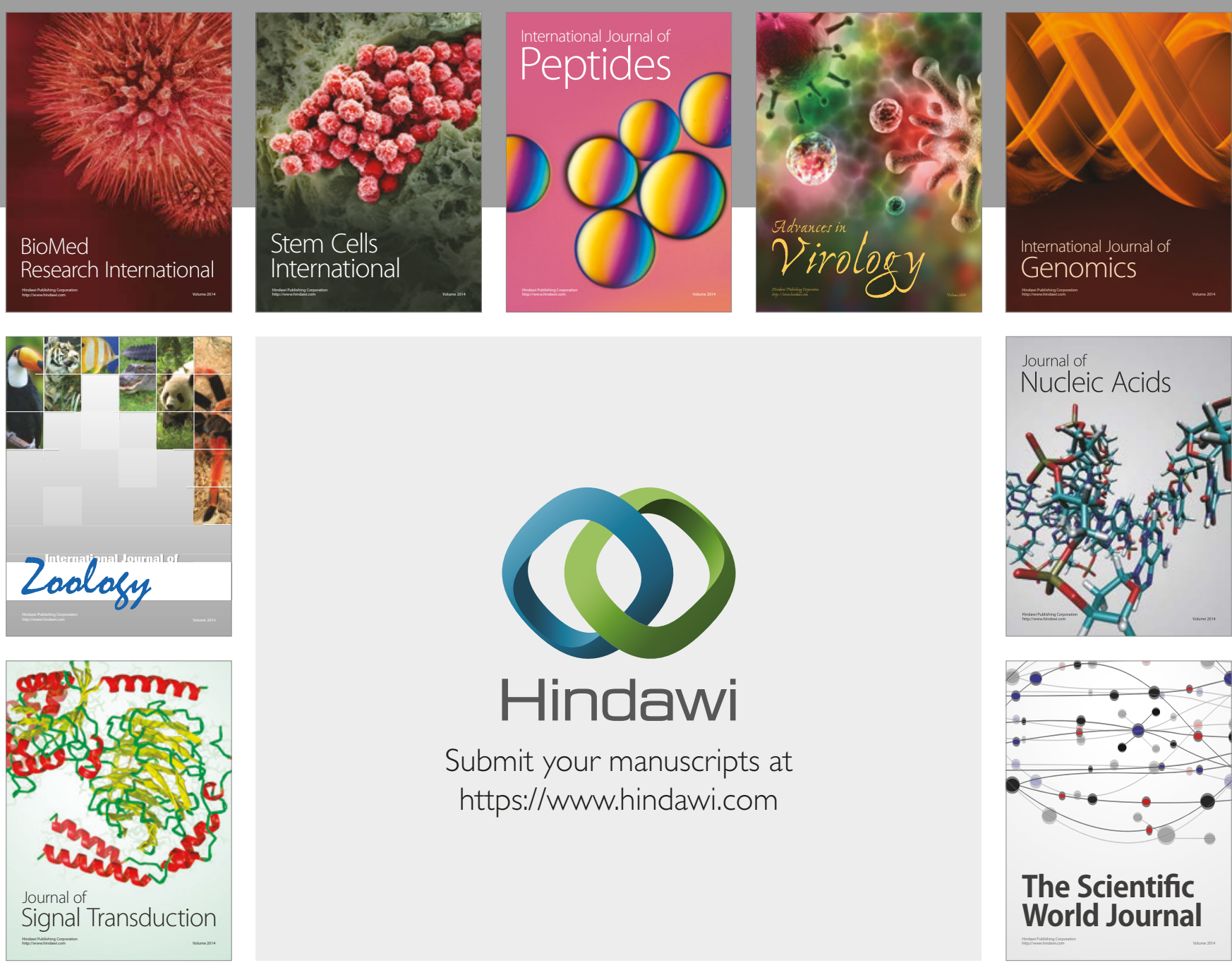

Submit your manuscripts at

https://www.hindawi.com
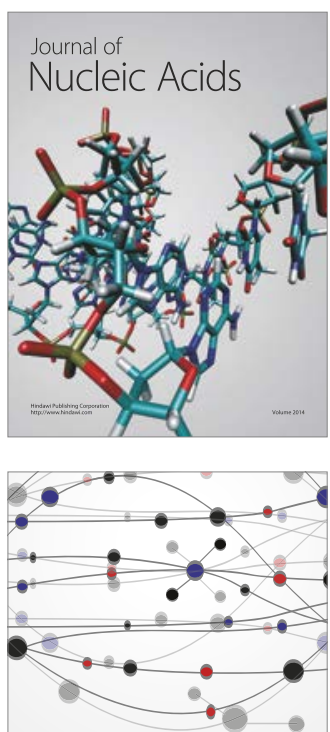

The Scientific World Journal

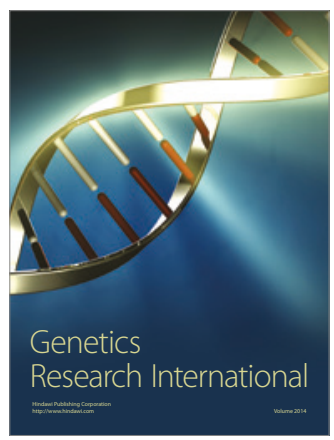

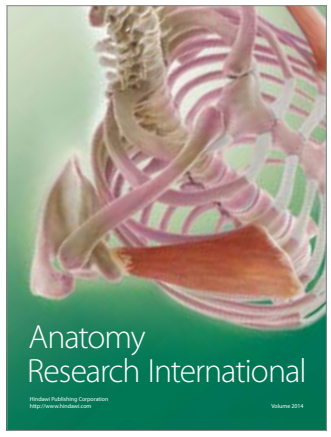

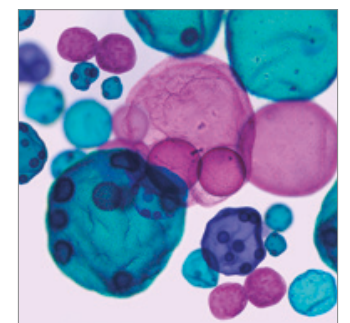

International Journal of Microbiology
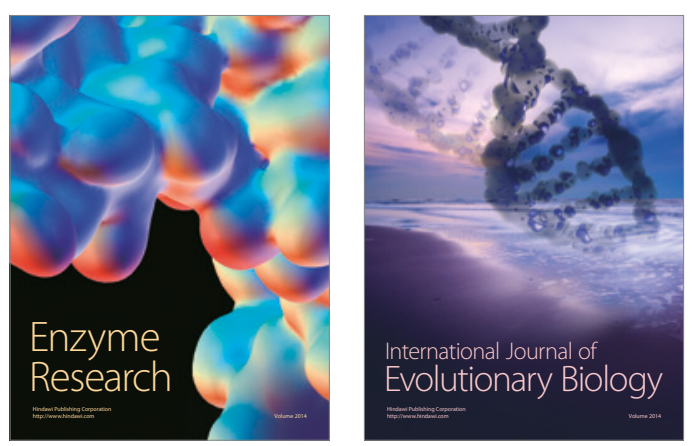
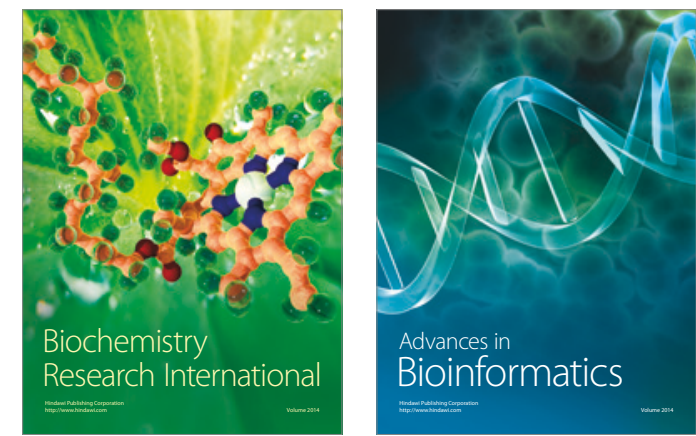

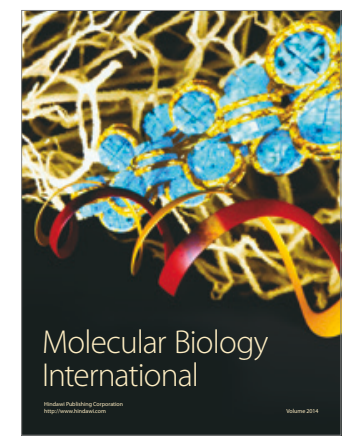

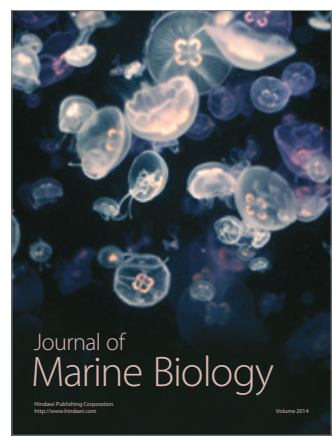

